\title{
STERILITY TESTING PROCEDURE OF OPHTHALMIC OCUSERT ACICLOVIR USED FOR TREATING HERPES SIMPLEX VIRUS
}

\author{
SHANMUGAM $S^{1}$, VALARMATHI ${ }^{2 *}$, SATHEESH KUMARS ${ }^{3}$ \\ ${ }^{1}$ Department of Pharmaceutics, Adhiparasakthi College of Pharmacy, Melmaruvathur, Kancheepuram, Tamil Nadu, India. ${ }^{2}$ Research Scholar, \\ Department of Pharmaceutics, School of Pharmacy, Vels University, (VISTAS) Chennai, Tamil Nadu, India. ${ }^{3}$ Department of Pharmaceutics, \\ School of Pharmacy, Vels University, (VISTAS) Chennai, Tamil Nadu, India. Email: sahanashree2012@gmail.com
}

Received: 17 April 2017, Revised and Accepted: 06 July 2017

\section{ABSTRACT}

Objective: The present work focuses on sterility studies of prepared aciclovir ocusert which is so essential for ophthalmic preparations. According to Indian Pharmacopoeia, the sterility test was performed. Ocuserts are sterile preparations which are placed into cul-de-sac or conjunctival sac. Ophthalmic inserts offer many advantages over conventional dosage forms such as increased ocular residence time, possibility of releasing drugs at a slow and constant rate and accurate dosing. Ocuserts are formulated for treating external ocular diseases such as conjuctivitis, corneal ulcer, and keratoconjuctivitis. Ophthalmic preparations contaminated with microorganisms cause corneal damage and finally blindness, especially if the microorganism is Pseudomonas aeruginosa. Ophthalmic preparations should be manufactured in aseptic condition and to be sterilized before packing.

Methods: According to Indian Pharmacopoeia, the official sterility test for ocusert was performed for detecting the presence of microbes. The selected F2 formulation which shows controlled drug release after 24 hrs was selected for the sterility test. The F2 formulation was subjected to ultraviolet radiation for sterilization. The sterilized ocusert and unsterilized ocusert were placed in fluid thioglycollate medium and incubated for 7 days at $20-25^{\circ} \mathrm{C}$.

Results: After 7 days of incubation, the sterilized ocusert shows no microbial growth and unsterilized ocusert shows microbial growth. The prepared aciclovir ocuserts were found to be sterile after the completion of official sterility test.

Conclusion: The sterility studies conclude after 7 days of incubation period; there was no appearance of turbidity which indicates the prepared formulation F2 was found to be sterile.

Keywords: Ocusert, Sterility test, Indian Pharmacopoeia, Ophthalmic drug delivery.

(c) 2017 The Authors. Published by Innovare Academic Sciences Pvt Ltd. This is an open access article under the CC BY license (http://creativecommons. org/licenses/by/4. 0/) DOI: http://dx.doi.org/10.22159/ajpcr.2017.v10i10.19216

\section{INTRODUCTION}

Ophthalmic is defined as dosage forms intended to be administered on to the external surface, inside and adjacent to the eye. Based on the site of administration, the ophthalmic is named as topical preparation, (external surface of the eye) intraocular preparation (inside the eye) and periocular preparations (adjacent to the eye).The capacity of eye to accommodate the dosage form is less, so they are administered in small amounts. Only small quantity of drug gets absorbed due to less contact time and quick drainage in the eye. The field of ocular drug delivery is one of the most interesting and challenging endeavors facing the pharmaceutical scientist. The usefulness of this route of drug administration can be easily appreciated because the drug enters the systemic circulation circumventing the hepatic first pass effect [1]. (1) Improving ocular contact time, (2) enhancing corneal permeability, and (3) enhancing site specificity [1].

Ophthalmic preparations are the sterile product, meant for the installation into the eye in the space between the eyelid and the eyeball. These products must be isotonic with lachrymal secretion to avoid discomforts and irritations. The $\mathrm{pH}$ should be controlled up to 8.0 to avoid irritations [2-4]. Vehicles in the preparation must have good wetting ability to penetrate cornea and other tissues. The anatomy of eye is shown in Fig. 1.

Ocusert system is a novel ocular drug delivery system based on porous membrane. The release of drug from diffusion inserts/ocusert is based on a diffusion release mechanism. It consists of a central reservoir of drug enclosed in specially designed micro porous membrane allowing the drug to diffuse from the reservoir at a precisely determined rate. Aciclovir is the prototype antiviral agent used to treat various types of herpes infections. Since aciclovir was the first antiviral to be considered the gold standard for the treatment of herpes infections; all other antiherpes virus medications are compared to it. The drug is approved for the treatment of herpes simplex keratitis, herpes simplex encephalitis, herpes genitalis, herpes labialis, herpes zoster, varicella (chickenpox), varicella-zoster virus, and viral conjunctivitis. It is approved for the prophylaxis of herpes genitalis. The aciclovir structural formula is shown in Fig. 2.

The desired criteria for a controlled release ocular inserts are:

- Comfort, lack of explosion, easy of handling and insertion, noninterference with vision and oxygen permeability, reproducibility of release kinetics, sterility, stability and easy of manufacture.

\section{Herpes virus}

Herpes simplex virus is a DNA virus that commonly affects humans. Infection occurs by direct contact of skin or mucous membrane with virus laden lesions or secretions. Herpes virus is shown in Fig. 3.

A polymer, natural or synthetic is a substance that is combined with a drug or other active agent to release drug in a predesigned manner $[5,6]$. Ocular inserts are least affected by nasolacrimal drainage, and tear flow thus provides reliable drug release and longer residence in cul-de-sac [7].

\section{METHODS}

All the ingredients used were of analytical grade. Aciclovir was received as a gift sample from Kaushik Therapeutics Pvt. Ltd., Chennai. Soya bean casein medium, agar, sodium hydroxide, potassium dihydrogen phosphate, ammonium chloride and calcium chloride was purchased from Qualigens Fine Chemicals, Mumbai. 
Sterility test [8-10]

Sterility tests were based on the principle that if bacteria or fungi are placed in a medium which provided nutritive material, moisture, and the desired $\mathrm{pH}$ and kept at a favorable temperature, the organism will grow and their presence can be indicated by the growth in originally medium. The tests for sterility were done by detecting the presence of viable forms of bacteria, fungi and yeast in or on preparations. The tests were carried out under strict aseptic techniques to avoid accidental contamination of the preparation.

\section{Sterility test for ocusert [11-13]}

The ocuserts were subjected to sterility test. The test for sterility was intended for detecting the presence of viable forms of bacteria, fungi, and yeast in preparations. The tests were carried out under aseptic conditions to avoid contamination of the product during the test.

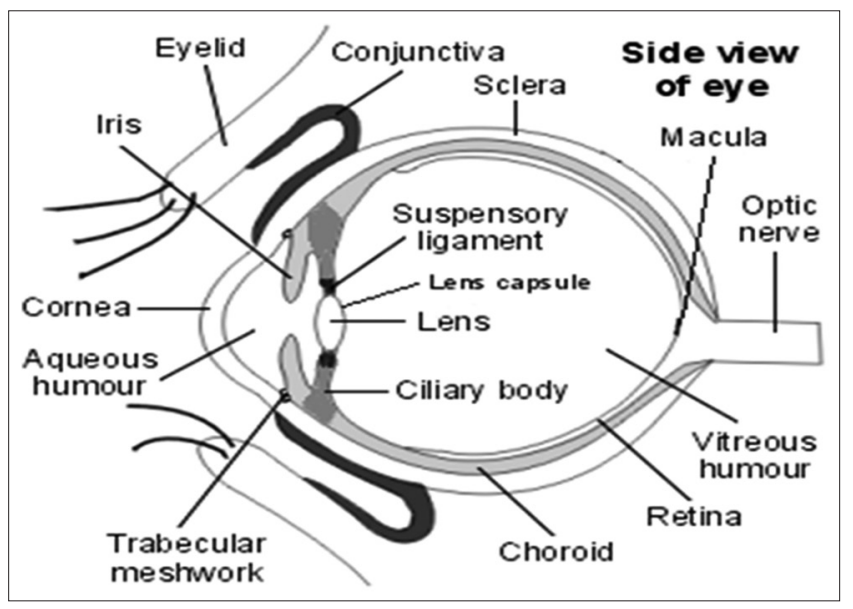

Fig. 1: Anatomy of eye

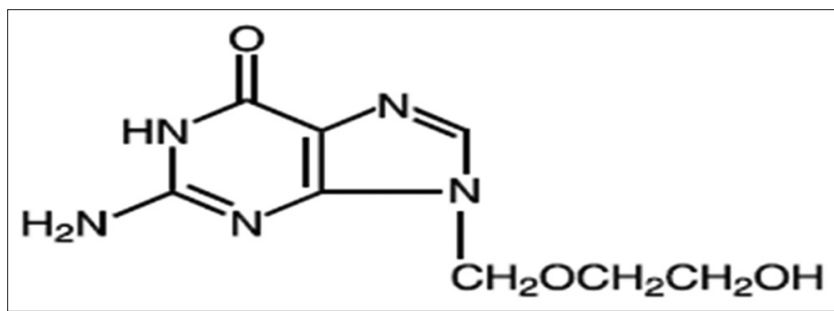

Fig. 2: Structural formula of aciclovir

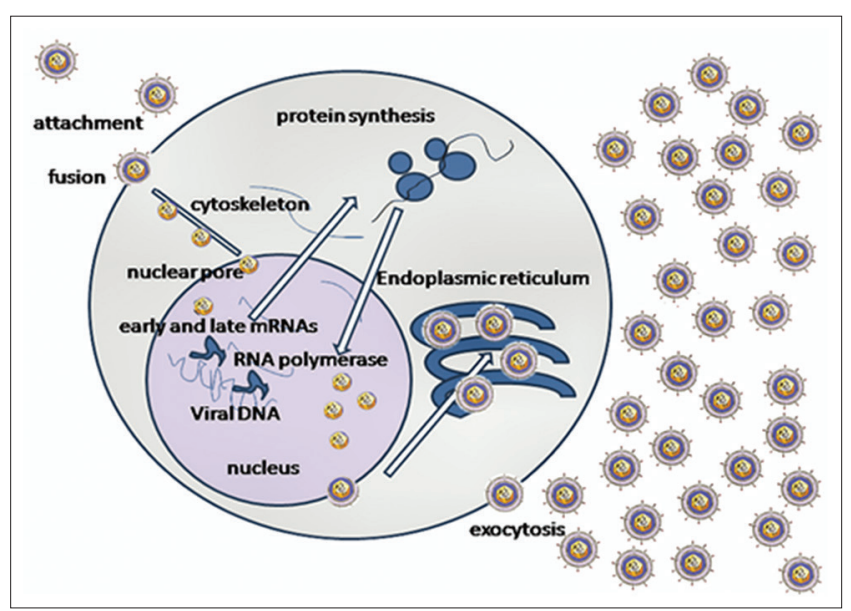

Fig. 3: Herpes virus
Culture media

For anaerobic bacteria and fungi.

Medium: Soya bean casein medium.

This medium can be used for the detection of anaerobic bacteria and fungi.

Preparation of soya bean casein medium

The ingredients pancreatic digest of casein $17 \mathrm{~g}$, papic digest of soya bean $3 \mathrm{~g}$, sodium chloride $2.5 \mathrm{~g}$, dibasic potassium phosphate $2.5 \mathrm{~g}$, and dextrose $2.5 \mathrm{~g}$ were dissolved completely in $1000 \mathrm{ml}$ of distilled water, and the medium was boiled for 10 minutes. The $\mathrm{pH}$ was adjusted to $7.3 \pm 0.2$. Media was distributed into $9 \mathrm{~cm}$ diameter Petri dishes.

\section{Sterilization of medium $[14,15]$}

Anaerobic culture medium was sterilized by autoclaving at a pressure of $15 \mathrm{l} \mathrm{lb}$ and a temperature of $121^{\circ} \mathrm{C}$ for 15 minutes. Autoclaved medium was kept in room temperature before inoculation of the sample.

\section{Incubation}

The sterilized ocuserts and unsterilized ocuserts were placed into fluid thioglycolate medium and incubated at $20-25^{\circ} \mathrm{C}$ for not $<7$ days. At specific intervals during the incubation period, the media were examined visually for microbial growth.

\section{Control test [16,17]}

To support the above-performed test, a positive control and negative control test were also carried out for quality control maintenance. Negative control test was carried out to confirm that the media and the environment provided for incubation were suitable for the growth of microorganism.

\section{RESULTS AND DISCUSSION}

\section{Sterility testing}

After in vitro drug release studies, best formulation F2 was selected. The selected formulation was sterilized by ultraviolet-radiation technique. Then, sterility testing was performed and the results were reported in Table 1.

Growth of microorganisms was noticed during the 7 days of incubation period in unsterilized ocusert, and there was no growth in sterilized ocusert. Thus, sterilized ocusert passes the test for sterility for anaerobic microorganism, and there was no growth which indicates ocusert can be used for ophthalmic purpose.

\section{CONCLUSION}

The sterility testing was very important evaluation for the ophthalmic preparations to check the presence of microorganisms. Because microorganisms presence in ophthalmic formulations may damage the eye and causes complete loss of vision. According to Indian Pharmacopoeia the sterility testing for the selected formulation F2 was carried out. The prepared ophthalmic ocuserts passes the sterility test as there was no turbidity appearance after the completion of the sterility test. As there was no appearance of growth of microorganisms, the ophthalmic ocuserts can be used for ophthalmic purpose.

\section{Table 1: Sterility testing results of selected formulation (F2)}

\begin{tabular}{ll}
\hline Type of ocusert & Growth of microorganism \\
\hline Negative control & Presence \\
Nonsterilized ocusert & Presence \\
Sterilized ocusert & Absent \\
\hline
\end{tabular}




\section{REFERENCES}

1. Jain MK, Manque SA, Deshpande SG. Controlled and Novel Drug Delivery. $1^{\text {st }}$ ed. New Delhi: CBS Publishers; 2005. p. 82-96.

2. Karthika K, Padmapreeth J. Comparative review on conventional and advanced ocular drug delivery formulations. Int J Pharm Pharm Sci Rev 2010;2(4):1-5.

3. Ibrahim HM, Ismail HR, Lila AE. Formulation and optimization of ocular poly-D,L-lactic acid nano drug delivery system of amphotericin-B using box behnken design. Int J Pharm Pharm Sci 2012;4(2):342-59.

4. Andonova V, Zagorchev P, Katsarov P, Kassarova M. Eye drops with nanoparticles as drug delivery systems. Int J Pharm Pharm Sci 2015;7:431-5

5. Robinson JC. In: Mitra AK, editor. Ophthalmic Drug Delivery Systems. New York: Marcel Dekker; 1993. p. 29-57.

6. Sintze MB, Bernatchez SF, Tabatabay C, Gurny R. Biomaterials in ophthalmic drug delivery. Eur J Pharm Biopharm 1996;42:358-74.

7. LeeVH, Robinson JR. Topical ocular drug delivery: Recent developments and future challenges. J Ocul Pharmacol 1986;2(1):67-108

8. Anonymous. Indian Pharmacopoeia. Vol. 1-2. New Delhi: The Controller of Publication, Govt. of India, Ministry of Health and Family Welfare; 2007. p. 52-9, 142-3, 565-8, 685-8.

9. Anonymous. The Merck Index. $14^{\text {th }}$ ed. USA: Merck Research
Laboratories; 2009. p. 26.

10. Anonymous. The United States Pharmacopoeia, NF 27. $32^{\text {nd }}$ ed., Vol. 1. Rockville, MD, USA: The United States Pharmacopeial Convention; 2009. p. 315, 1427-31.

11. Arora DR, Arora B. Text Book of Microbiology. $3^{\text {rd }}$ ed. New Delhi: CBS Publishers and Distributors; 2008. p. 537-47.

12. Balasubramanian J, Srinatha A, Pandit JK, Nath G. In-vitro microbiological evaluation of polyvinyl alcohol based ocular inserts of ciprofloxacin hydrochloride. Indian J Pharm Sci 2003;68(5):626-30.

13. Bagool MA. Topical ocular drug delivery a review. Indian Drugs 1993;31(10):451-6.

14. Chari SS, Makoid MC, Erikson SP, Robinson JR. Drop size and initial dosing frequency problems of topically applied ophthalmic drugs. J Pharm Sci 1974;64:333-8.

15. Dandagi PM. Development and evaluation of ocular films of cromolyn sodium. Indian J Pharm Sci 2004;66(3):309-12.

16. Nithiyananthan TS, Shankarananth V, Rajasekhar KK, Jyothikrishna K, Mukesh O, Kumar EV, et al. Preparation and evaluation of ciprofloxacin ousters. J Pharm Res 2009;2(9):1496-9.

17. Chandran CS, Shirwalkar A, Kiron SS. Development and evaluation of chitosan containing ciprofloxacin-B CD complex. Int J Pharm Technol Res 2010;2(1):246-52. 